\title{
Carlos Germán Belli y Jorge Eduardo Eielson. UN ENSAYO DE RETÓRICA COMPARADA *
}

\section{Camilo Fernández-Cozman**}

\section{Resumen}

Carlos Germán Belli y Jorge Eduardo Eielson son dos poetas peruanos. El autor intenta comparar la obra de ambos poetas sobre la base del análisis de las figuras literarias y de las técnicas argumentativas. Se trata de una óptica de Retórica Comparada. Los dos poetas realizan una crítica de las estructuras de poder hegemónico y ello se evidencia en dos poemas representativos: “La ración" y "Cappella Sistina".

Palabras clave: metáfora, argumentación, poesía, poder.

\section{Carlos Germán Belli and Jorge Eduardo Eielson. AN ESSAY ON COMPARATIVE RHETORIC}

\begin{abstract}
Carlos Germán Belli and Jorge Eduardo Eielson are two Peruvian poets. The author attempts to compare the work of two poets on the basis of analysis of literary figures and argumentative techniques. It is a perspective of Comparative Rhetoric. The two poets made a critique of hegemonic power structures and this is evident in two representative poems: "The ration" and "Cappella Sistina".
\end{abstract}

Keywords: metaphor, argumentation, poetry, power.

Recibido: 02-05-2015

Aceptado: $14-10-2015$

* Este artículo forma parte de la investigación “Hacia una Retórica Comparada en el análisis de la poesía peruana" que el autor desarrolla en la Universidad San Ignacio de Loyola.

* Peruano. Doctor en Literatura Peruana y Latinoamericana por la Universidad Nacional Mayor de San Marcos (Lima). Es catedrático en la Universidad San Ignacio de Loyola (Lima). Camiloruben@ gmail.com 


\section{Introducción}

La Retórica Comparada implica el acto de confrontar dos o más textos o autores en relación con los recursos persuasivos que se emplean de modo recurrente en cada uno de los discursos literarios. Pueden ser metáforas, metonimias o técnicas argumentativas, entre otros recursos expresivos. Dicha disciplina se nutre de tres fuentes. La primera es la Retórica General Textual que se halla representada por Antonio García Berrio (1989), Giovanni Bottiroli (1993, 1997, 2006) y Stefano Arduini $(2000,2004)$ quienes superan la óptica de la retórica restringida que solo se limitaba a una descripción minuciosa de las figuras literarias y dejaba de lado el vínculo entre una metonimia y un tema; o entre una sinécdoque y la ideología del autor.

Arduini aportó dos categorías fundamentales: campo retórico y campo figurativo. El primero "es la vasta área de los conocimientos y de las experiencias comunicativas adquiridas por el individuo, la sociedad y por las culturas" (Prolegómenos... 47). En dicho ámbito se sitúan los procesos de recepción de las obras literarias y el vínculo que estas últimas establecen con ciertas corrientes literarias, artísticas o de pensamiento. Cuando nos preguntamos sobre cómo Roberto Paoli leyó a César Vallejo, estamos indagando en una experiencia comunicativa por la cual se descifra un poema vallejiano desde una determinada óptica teórica. Asimismo, cuando calificamos a Guillaume Apollinaire como poeta cubista, estamos adscribiendo la obra de este en la esfera del cubismo como corriente estética. Ello implica el conocimiento que poseía Apollinaire de dicha escuela artística. En los dos casos, sin duda, nuestro análisis pone de relieve el funcionamiento del campo retórico. En lo que concierne al campo figurativo, resulta pertinente señalar que se trata de un ámbito cognitivo que permite incluir las distintas figuras literarias en seis categorías del pensamiento: la metáfora, la metonimia, la sinécdoque, la elipsis, la antítesis y la repetición. Por ejemplo, pensamos metafóricamente cuando concebimos que una casa es un cuerpo y que los pilares de ella son los brazos. En el campo figurativo de la metáfora se ubican figuras retóricas como el símbolo, la personificación, el símil o la metáfora en tanto procedimiento figurativo específico; en el de la metonimia se incluyen todos los tipos de metonimia como aquellos que se basan en la relación de causa-efecto, efecto-causa, continentecontenido, entre otros casos; en el de la sinécdoque se encuentran 
todas las clases de sinécdoque como las que se sustentan en la relación parte-todo, todo-parte, género-especie, especie-género, verbigracia; en el de la elipsis, tenemos el asíndeton, el silencio (la página en blanco mallarmeana), la perífrasis, el eufemismo, el zeugma, por ejemplo; en el de la antítesis, podemos reconocer figuras retóricas como la ironía, el oxímoron, la paradoja, la antítesis como mecanismo figurativo, entre otras posibilidades. En gran medida, el campo figurativo se sitúa en las estructuras profundas e involucra la coherencia de la visión del mundo del poeta. Por el contrario, la figura retórica se ubica en la estructura superficial, es decir, en el plano de la cohesión textual; sin embargo, no constituye -tal como lo planteaba Pierre Fontanier (1977) en el siglo XIX o el Grupo $\mu$ (1982) en los años setenta del siglo pasado- un desvío respecto de la norma. Para Arduini, la figura retórica es un universal antropológico de la expresión. Como afirma el lingüista italiano, se trata de:

Procesos (...) antropológico-expresivos. Antropológicos, en el sentido de que atañen a una característica específicamente humana, y expresivos, porque se refieren a los medios con que el hombre organiza su propia facultad comunicativa; por tanto, tales procesos no están limitados solamente a la expresión verbal. Así, a título de ejemplo, para las figuras podemos pensar que opera el inconsciente, el imaginario, el ceremonial, el mito. Pero, más generalmente, las figuras se sitúan como elementos nodales de todos los fenómenos ligados al comportamiento expresivo humano. En ese sentido, las figuras recubren el campo de lo simbólico y el campo de lo sígnico. Insistiría, por tanto, en el hecho (...) de que la figura no hace más que acoger sobre el plano de la cohesión potencialidades más profundas. (Prolegómenos... 136)

La segunda fuente es la Retórica Cultural, cuyo máximo exponente es Tomás Albaladejo (1991, 2008, 2009), quien inició su labor teórica en el ámbito de la Retórica General Textual, pero luego pasó a interesarse en una perspectiva cultural sobre la base de la asimilación creativa de los aportes de la semiótica de Yuri Lotman y de la teoría de la polifonía de Mijail Bajtín. El primero había planteado la idea de que la literatura era un sistema modelizador secundario (Lotman, 1978). El segundo proyectó en su concepción de la novela la noción de polifonía (Bajtín, 
1986, 1989) para estudiar la producción novelística de Fedor Dostoievski. Un concepto fundamental para comprender la perspectiva de la Retórica Cultural es el de poliacroasis (Albaladejo, 2009). Consiste en la audiencia múltiple, es decir, se trata de abordar cómo un locutor se dirige a varios alocutarios en el mundo representado en el poema. Por ejemplo, esta particularidad se manifiesta en "Alturas de Macchu Picchu" de Pablo Neruda, donde el locutor se dirige a muchos alocutarios (Fernández Cozman, 2014b) empleando varios vocativos: Macchu Picchu, el amor americano, Juan Cortapiedras, entre otros:

Juan Cortapiedras, hijo de Wiracocha,

Juan Comefrío, hijo de estrella verde,

Juan Piesdescalzos, nieto de la turquesa,

sube a nacer conmigo, hermano (36).

Consideramos que la poliacroasis es una característica de lo que hemos denominado la poesía intercultural en América Latina (Fernández Cozman, 2004, 2011, 2014a, 2014b) que se revela en autores como Pablo Neruda, César Vallejo, Octavio Paz, Ernesto Cardenal, Antonio Cisneros y José Emilio Pacheco, entre otros. En tal sentido, la poesía intercultural implica un diálogo (no exento de conflictos) entre las culturas occidentales y las amerindias, y ello se revela en cuatro niveles: la lengua, la estructuración literaria, las estructuras figurativo-simbólicas y la cosmovisión (Fernández Cozman, 2004). Por ejemplo, Neruda trabaja en los cuatro niveles simultáneamente en Canto general: emplea un registro coloquial literaturizado (estrato de la lengua), reestructura creativamente el poema épico clásico (plano de la estructuración literaria), emplea magistralmente metáforas para referirse a Macchu Picchu (nivel de las estructuras figurativo-simbólicas) y concibe que el hombre americano nació del maíz (esfera de la cosmovisión). Por eso, la Retórica Cultural provee de categorías teóricas, como la poliacroasis, para analizar la poesía intercultural en América Latina.

La tercera fuente de la Retórica Comparada es la Retórica de la Argumentación, que tiene como principales representantes a Chaïm Perelman y Lucien Olbrechst-Tyteca (2008), quienes distinguieron entre 
argumentos analíticos (basados en las ciencias formales) y los dialécticos, donde prima el propósito de un orador para convencer al auditorio. Sin duda, Perelman y Olbrechst-Tyteca concebían la noción de un auditorio universal (los filósofos, a veces, se dirigen a este tipo de audiencia) o de aquel constituido solo por un único oyente; asimismo, abrían la posibilidad de que el orador pudiera deliberar consigo mismo, aunque siempre este tenía en la mente las posibles objeciones que un receptor potencial pudiera formularle en un contexto hipotético. Pensamos que existen poemas argumentativos (Fernández Cozman, 2012, 2014c) que plantean una tesis u opinión bien fundamentada como en Canto general o Poemas humanos. En otros casos, hay textos poéticos que emplean recursos argumentativos sin llegar a sustentar una tesis y lo hacen con fines claramente persuasivos. Ello se puede observar en algunos escuetos poemas de José Emilio Pacheco, Nicanor Parra o Ernesto Cardenal.

Sin duda, hay un lazo innegable entre la Retórica Comparada y la Literatura Comparada: ambas disciplinas tienen como ostensible propósito la confrontación de textos enfatizando semejanzas y diferencias. Sin embargo, la Retórica Comparada privilegia, a diferencia de la Literatura Comparada, el cotejo de procedimientos figurativos y técnicas argumentativas, con fines persuasivos, entre dos o más textos. En otras palabras, aquella concibe al poeta como si fuera un orador que tiene como primordial propósito convencer al auditorio a través de metáforas o argumentos de autoridad, por ejemplo. El locutor intenta, en tal sentido, persuadir al alocutario en el universo representado por el poema.

Además, hay un concepto de Albaladejo $(2008,2009)$ que es fundamental para comprender a cabalidad la Retórica Comparada: el análisis interdiscursivo. Albaladejo afirma que no se trata solo de comparar textos del mismo género (dos cuentos entre sí, verbigracia), sino también disciplinas y discursos de diversa modalidad. Por ejemplo, cotejar una metáfora, presente en un poema simbolista, con otra que se manifiesta en un ensayo literario. Una nueva posibilidad de análisis sería confrontar una técnica argumentativa que se emplea en una novela de crítica política con otra que se revela en un tratado de antropología, verbigracia. 


\section{Dos poetas peruanos de la generación del cincuenta: Carlos Germán Belli y Jorge Eduardo Eielson}

El objetivo de nuestro artículo es comparar a dos autores peruanos de la denominada generación del cincuenta: Carlos Germán Belli (Lima, 1927) y Jorge Eduardo Eielson (1924-2006). El primero obtuvo el Premio Iberoamericano de Poesía Pablo Neruda en 2006; el segundo, el Premio Nacional de Poesía en 1945, entre otros galardones. Para comprender plenamente la obra de ambos poetas, resulta pertinente recordar la periodización de la poesía peruana, desde la época colonial hasta los años setenta del siglo pasado, que realiza Alberto Escobar (1973), quien señala que existen cuatro etapas. La primera es la de los mantenedores de la tradición hispánica y allí se ubican las poetisas Amarilis (autora de "Epístola a Belardo", una emotiva carta-poema dirigida a Lope de Vega) y Clarinda (quien escribió "Discurso en loor a la poesía", una loa al estro poético), además de Juan Valle Caviedes (poeta satírico que se burlaba de los médicos de su época sobre la base de un estilo barroco), Pedro Peralta y Barnuevo (cuya vena poética se revela en Lima fundada) y Diego de Hojeda, que produjo un poema religioso cuyo título es $L a$ cristiada. La segunda es la de los buscadores de las tradiciones propias, y en ese período se ubican autores como Mariano Melgar (quien escribió yaravíes, cantos de amor herederos del haraui andino prehispánico), los poetas románticos peruanos (como Ricardo Palma, Carlos Augusto Salaverry y Clemente de Althaus), José Santos Chocano (modernista, pero más propenso a la estética parnasiana), Manuel González (político, antecedente del indigenismo y buscador de nuevas formas estróficas) y Abraham Valdelomar (cuentista notable, pero poeta posmodernista que aborda temas como el hogar provinciano en "Tristitia" y El hermano ausente en la cena de pascua". La tercera etapa es la de los fundadores de las tradiciones poéticas peruanas. José María Eguren, con Simbólicas (1911), marca el inicio de la lírica contemporánea en el Perú y es un poeta ejemplar. En este período se sitúan César Vallejo, una de las cumbres de la poesía en lengua castellana, quien con Trilce (1922) produjo una revolución vanguardista sin precedentes. Cabe mencionar, en el ciclo de los fundadores, a poetas vanguardistas como Emilio Adolfo Westphalen, César Moro, Martín Adán (quien produjo sonetos vanguardistas), Alejandro Peralta y Carlos Oquendo de Amat. Belli y Eielson, como 
poetas de la llamada generación del cincuenta, forman parte de la etapa de los fundadores, junto a Blanca Varela, Javier Sologuren, Alejandro Romualdo, Juan Gonzalo Rose, Wáshington Delgado y Efraín Miranda (Fernández Cozman, 2010). Escobar añade un cuarto período: el de los cuestionadores de las tradiciones poéticas peruanos, donde se ubican los representantes de las llamadas generaciones del sesenta (Antonio Cisneros, Rodolfo Hinostroza, Marco Martos, Luis Hernández, Juan Ojeda, Javier Heraud, entre otros) y del setenta (Enrique Verástegui, José Watanabe, Tulio Mora, Abelardo Sánchez León, por ejemplo). Estos autores destacan por la asimilación de los aportes de la lírica de lengua inglesa (Ezra Pound, T.S. Eliot, verbigracia) y por someter a tela de juicio los aportes de César Vallejo, entre otros autores.

La crítica especializada (Hill, 1985; Cánepa, 1987; Cornejo Polar, 1994; Paoli, 1994; Sobrevilla, 2006) ha puesto de relieve cómo en la poesía de Belli se da una lucha entre el estilo tradicional (el uso de la sextina, por ejemplo) y el vanguardista (metáforas surrealistas al lado de giros coloquiales, verbigracia); asimismo, ha analizado de qué manera en la obra poética de Eielson se percibe una tendencia neovanguardista (Fernández Cozman, 1996) y cómo este poeta explora el espacio de la página en blanco (Rowe, 2002) o indaga por la dimensión corporal del ser humano a través del empleo de símbolos oníricos y de la mutación de la materia (Canfield, 2002). Otros investigadores, entre lo que destaca Morillo (2014), han intentado confrontar la poesía de Eielson con sus propias reflexiones sobre el hacer poético con el fin de precisar una intertextualidad que permita iluminar los principales ejes temáticos de la obra del autor de Habitación en Roma.

Belli y Eielson comparten, obviamente, una vocación experimental que se evidencia en dos poemarios notables: El pie sobre el cuello y Habitación en Roma. ¿Cuál fue la razón que nos impulsó a elegir esos dos libros? Creemos que en ambos se observa el tema del poder con meridiana claridad. Los títulos de los volúmenes son de índole metonímica. El de Belli implica el empleo de la metonimia de instrumento: el pie representa (es un instrumento) el poder ejercido contra el cuerpo; en cambio, el poemario de Eielson muestra, de modo palpable, la metonimia de lugar para evidenciar la imposición del discurso del poder hegemónico:

Decir Roma en vez de catolicismo constituye una metonimia de lugar. Habitación en Roma quiere decir, en principio, habitación 
en el mundo tecnológico, pues la presencia de los medios audiovisuales, de los avisos luminosos, de la tecnología atómica configura una de las problemáticas medulares de la modernidad (Fernández Cozman, Las huellas... 115-6).

Hay algo que aparece en los dos poemarios: el empleo de topónimos. Eielson alude a Roma, a Hiroshima y a las distintas calles de la capital de Italia. Belli, por su parte, tiene dos referencias al Perú muy significativas en un libro de tan corta extensión. Los dos poetas emplean giros coloquiales. Eielson los utiliza de manera más directa; por su parte, Belli los mezcla creativamente a una sintaxis clásica de algunos ecos barrocos. Eielson nombra a protagonistas vinculados al arte: Giuseppe Ungaretti y Miguel Ángel Bounarrotti, verbigracia; por el contrario, Belli designa personajes o lugares mitológicos: Cupido, Erídano, Leteo, Betis, entre otros. Ambos escritores abordan el tema de la pobreza económica. En el primer texto de Habitación en Roma se afirma que "un animal tan milagroso/ carecería de vientre / no tendría tantos hijos / negros blancos amarillos / que amanecen diariamente/ con la cara ensangrentada / y los brazos amarrados / con la lengua acuchillada/ y el estómago vacío" (Eielson, Poesía escrita 156). En "Amanuense" se dice: "aunque en verdad yo por mi seso raso, / y aun por lonjas y levas y mandones, / que a la zaga me van dejando estable, / ya a más hasta el gollete no poder, / al pie de mis hijuelas avergonzado, cual un pobre amanuense del Perú" (Belli, Los versos... 110). En tal sentido, los dos poetas son herederos de César Vallejo (1991), quien, en "La cena miserable" o "La rueda del hambriento", abordó la pobreza económica como eje temático fundamental. A diferencia de Poemas humanos donde el poeta de Santiago de Chuco vislumbra una utopía de justicia social (recuérdese el poema "Los desgraciados"), Belli y Eielson no perciben una salida a la crisis de la modernidad: el poder es ejercido, de modo violento, por los representantes del grupo hegemónico ("los mandones", para Belli; la cultura audiovisual y la tecnología nuclear, para Eielson).

Otro aspecto en el cual convergen ambos vates es la concepción del trabajo. Es pertinente mencionar que Poemas humanos constituye un antecedente de dicha idea, pues allí los mineros son vistos como intelectuales que unen, de manera fecunda, la teoría a la práctica. En los poemarios Habitación en Roma y El pie sobre el cuello, la actividad laboral se vincula con la deshumanización del hombre. En Habitación en Roma, leemos: "señores que sonríen y sonríen/ y operarios que trabajan 
y trabajan/ con miserables avenidas / que huelen a ropa sucia" (Eielson, Poesía escrita 173). El amanuense, en El pie sobre el cuello, realiza una actividad degradante y, por lo tanto, nada creativa si la comparamos al acto lúdico y gratificante de escribir un poema.

Eielson es más neovanguardista que Belli y juega con el espacio en blanco de la página a la manera de Carlos Oquendo de Amat. En cambio, Belli busca un equilibrio (no exento de conflicto) entre lo clásico y el arte de vanguardia. Sin duda, trae a la memoria Travesía de extramares de Martín Adán, donde el soneto ora clásico, ora barroco, se entremezcla con giros metafóricos de índole vanguardista.

\section{2. "La Ración" de Carlos Germán Belli frente a "Cappella Sistina" de Jorge Eduardo Eielson}

Ahora nos centraremos en la retórica comparada de dos escuetos pero significativos poemas: "La ración" (de El pie sobre el cuello) y "Cappella Sistina" (de Habitación en Roma), pues estos desarrollan el tema de la imposición de los grupos hegemónicos. Transcribiremos los dos textos:

\section{La ración}

Bien que con mi gollete yo al duro cepo,

sin culpa alguna desde siete lustros,

y en mis barbas a su bastón asidos

los crueles amos blancos del Perú,

mirándome burlonamente siempre,

de mandatos armados mil se yerguen;

no hay día que mi olfato no traspase

los umbrales del suelo, el agua, el aire

a oliscar la ración siquiera de un átomo

para la boca de mis dos hijuelas,

o descienda hasta el fuego impenetrable

por unas migas ya carbonizadas (Belli 107). 


\section{Cappella Sistina}

Hay personas

correctamente vestidas de gris

con camisa y corbata ciertamente

que a duras penas son personas

personas que se aventuran

con sus mil ojos cerrados

de escarabajos

bajo la cúpula divina

del florentino

personas que se arrodillan

ante sus pantorrillas

y sus inmensos traseros encendidos

antropófagos sin dientes

que ya no muerden sino admiran

sobre la pantalla atroz de la sixtina

en la carnicería final del bounarrotti

el sangriento banquete de un magnate

o una película en colores

sobre hiroshima (Eielson 197).

En ambos poemas predomina una crítica al poder hegemónico. Belli alude a "los crueles amos blancos del Perú". Eielson hace referencia a personas que "están correctamente vestidas de gris/ con camisa y corbata ciertamente". En los dos casos se desarrolla el acto de comer como una expectativa frustrada. "La ración" termina con la idea de "unas migas ya carbonizadas". Por el contrario, "Cappella Sistina" subraya la idea de "antropófagos sin dientes". Desde el punto de vista figurativo, Belli prefiere el hipérbaton como recurso estilístico tan caro a la estética barroca. Eielson enfatiza el empleo de la repetición: la palabra "personas" se itera obsesivamente a lo largo del discurso poético. 
Para Eielson, la Capilla Sixtina se ha convertido en una película en colores sobre Hiroshima, es decir, el discurso del poder lo ostenta la cultura audiovisual, manejado por los magnates, quienes defienden la tecnología nuclear. En otras palabras, la obra de arte renacentista se ha transformado, inopinadamente, en un discurso de agresión al otro. Pareciera que la realidad ha superado a la ficción: el discurso artístico de Miguel Ángel Bounarrotti ha mutado, de modo súbito, en una carnicería humana como secuela del empleo de la tecnología nuclear. Para ello, Eielson emplea un pensar metafórico: unas personas son "antropófagos sin dientes" y semejan escarabajos que poseen "mil ojos cerrados". Esa estructura cognitiva, basada en la analogía, se completa con la antítesis como campo figurativo: "ya no muerden sino admiran". También dicha particularidad se revela en el uso de la paradoja como figura retórica: "Hay personas (...)/ que a duras penas son personas". A ello se suma la utilización notable de otro campo figurativo, el de la repetición, que se manifiesta no solo en la iteración de la palabra "personas", sino en la enumeración final que agrupa elementos y posibilita el remate magistral del poema.

Para Belli, los sectores hegemónicos en el Perú se han erigido como los dueños del país desde hace varios lustros. Por ello, a diferencia de Eielson, no aborda Roma como tema, sino el Perú; sin embargo, hay algo que hermana temáticamente a los dos poemas: el discurso de la violencia no solo se encuentra en las grandes metrópolis, sino en países periféricos como el Perú. El poeta emplea el cepo como un símbolo de opresión que se halla situado en el campo figurativo de la metáfora. Agrega el campo figurativo de la repetición que, como en el texto de Eielson, implica el funcionamiento de un bloque enumerativo: "los umbrales del suelo, el agua, el aire". Pensamos que, a diferencia del poema de Eielson, en "La ración" predomina el pensar antitético porque se traduce la lucha entre los distintos grupos sociales: el de los mandones (el término es de Belli) y el de los desvalidos.

Hay otra diferencia: en "Cappella Sistina" predomina el locutor nopersonaje que se dirige a un alocutario no representado; vale decir, se trata de una perspectiva externa. El hablante contempla solo la escena y percibe cómo los actores se mueven en el escenario. Por el contrario, en "La ración", prepondera el locutor personaje que se dirige a un alocutario no representado. Por eso, prevalece el tono de monólogo que se evidencia 
en el uso recurrente de los posesivos: "mi gollete", "mis barbas", "mi olfato" y "mis dos hijuelas".

Ahora bien, ¿cómo el locutor busca convencer al alocutario? Pensamos que los dos poemas son de índole argumentativa. La tesis de Belli es que los sectores hegemónicos condenan al hambre al sujeto pobre, quien tiene prole y solamente alcanza una ración de comida ya carbonizada. La tesis de Eielson es que las clases dominantes se deshumanizan y convierten una obra de arte de Miguel Ángel en una pantalla de cine donde se elogia tanto la bomba atómica como la cruenta carnicería de seres humanos.

¿Cuáles son las técnicas argumentativas que emplea el locutor para convencer al alocutario? Chaïm Perelman y Lucie Olbrechts-Tyteca (2008) afirman que existen cinco tipos de técnicas argumentativas: los argumentos casi lógicos (el entimema o el de la definición, por ejemplo), los basados en la estructura de lo real (el de autoridad o el de la coexistencia, verbigracia), los enlaces destinados a fundamentar la estructura de lo real (el ejemplo o el modelo o antimodelo, como casos representativos), la disociación de las nociones (vida frente a muerte, o vigilia frente a sueño) y la interacción de los argumentos, vale decir, la manera como estos se complementan, de manera fecunda, a lo largo de un poema.

En los dos poemas predomina un enlace destinado a fundamentar la estructura de lo real: el antimodelo. Sin duda, "los crueles amos blancos del Perú" y los individuos "que a duras penas son personas" constituyen antimodelos porque personifican valores profundamente negativos en el universo representado en cada uno de los textos.

El locutor, en el poema de Eielson, utiliza un argumento casi lógico, es decir, el basado en una definición cuando califica a dichas personas como "antropófagos sin dientes". Por el contrario, en el texto de Belli, predomina el argumento basado en la estructura de lo real, es decir, el de la coexistencia. Ello se evidencia cuando una característica peculiar es atribuida a un personaje o edad histórica. Por ejemplo, la Edad Media se caracteriza por el feudalismo; la modernidad, por el capitalismo. En "La ración", el locutor se halla atado al cepo y dicha particularidad tan significativa lo cataloga como un sujeto oprimido y condenado a una vida plenamente deshumanizada. 
En ambos poemas, para sustentar su tesis, se utilizan los argumentos de la dirección que se basan en determinadas metáforas orientacionales, así son calificadas por Lakoff y Johnson (2003) en su clásico libro Metáforas de la vida cotidiana, ya que ponen de relieve las oposiciones alto/bajo, izquierda/derecha, rodeante/rodeado, entre otras posibilidades. Por ejemplo, en "Cappella Sistina", se afirma "bajo la cúpula divina del florentino". Por su parte, en "La ración", se abre la posibilidad de descender "hasta el fuego impenetrable/ por unas migas ya carbonizadas". En otras palabras, la fuerza argumentativa de los dos textos se sostiene en una organización espacial que se evidencia en la oposición alto-bajo.

\section{3. "Poema" de Carlos Germán Belli frente a "Via Della Croce" de Jorge Eduardo Eielson}

Ahora pasaremos a confrontar otros dos textos, uno de Belli y otro de Eielson:

\section{Poema}

Frunce el feto su frente

y sus cejas enarca cuando pasa

del luminoso vientre

al albergue terreno,

do se truecan $\sin$ tasa

la luz en niebla, la cisterna en cieno;

y abandonar le duele al fin el claustro,

en que no rugen ni cierzo ni austro,

y verse aun despeñado

desde el más alto risco,

cual un feto no amado,

por tartamudo o cojo o manco o bizco (Belli 106). 


\section{Via della Croce}

frecuentemente

cuando estoy sentado

en una silla

y estoy solo

y no he dormido

ni comido ni bebido

ni amado

tengo la impresión

de caer en un abismo

amarrado a mis vestidos

y a mi silla

y de irme muriendo suavemente

acariciando mis vestidos

y mi silla

tengo la impresión

de caer en un abismo

y de improviso asistir

a una remota fiesta

en el fondo de una estrella

y de bailar en ella

tiernamente

con mi silla (Eielson 160).

Los dos poemas comparten una metáfora orientacional (Lakoff y Johnson, 2003). Belli pone de relieve el tránsito del útero materno al materno; por el contrario, Eielson se detiene en la caída, vale decir, en el desplazamiento desde la esfera de lo alto a lo bajo a través de la contundente imagen del abismo. Además, en ambos textos se percibe 
la soledad del locutor, quien monologa y, en tal sentido, se dirige a un alocutario no representado. No hay ningún individuo que acompañe al hablante en el universo representado. El sujeto se halla arrojado al mundo violentamente en "Poema", mientras que en "Via della Croce" únicamente está acompañado por su silla. En el poema de Belli hay un tono más clásico y una alusión a la mitología grecolatina (se habla del austro); en cambio, en el de Eielson se suprime la puntuación a la manera vanguardista y se desarrolla una poética de la caída, heredera, en cierto modo, de Altazor de Vicente Huidobro.

Quisiéramos detenernos en el abordaje de los procedimientos retóricos. El campo figurativo de la repetición se manifiesta en los dos textos. "Poema" empieza con una aliteración contundente que subraya la extrañeza del feto que se encuentra, desvalido, en el mundo terrenal. "Via della Croce" evidencia el empleo del polisíndeton y de la iteración obsesiva del sintagma " $\mathrm{mi}$ silla", hecho que revela un mundo minimalista, vale decir, reducido a sus mínimos elementos: parece que el ser humano estuviera separado de los demás. En los dos casos se subraya la carencia. Belli acentúa las limitaciones físicas del hablante, quien es marginado porque es cojo o tuerto o manco o bizco. Eielson recalca que el locutor personaje no ha comido, vale decir, nuevamente se muestra, de modo ostensible, la pobreza económica, un tema tan caro a la poética de César Vallejo, quien escribió "La cena miserable" o "La rueda del hambriento" para cuestionar el papel que cumplen los grupos hegemónicos que condenan a la orfandad al sujeto pobre.

Hay, sin embargo, una coincidencia que resulta interesante. Belli habla del acto de despeñarse "desde el más alto risco" para convertirse en un feto despreciado. Eielson alude a la caída en el abismo; pero, al final, imagina un baile con la silla que sustituye afectivamente a otro ser humano. ¿La soledad invade la cotidianidad del hombre hasta en los mínimos detalles?

Existe una diferencia. La sinécdoque predomina en el texto de Belli: la frente y las cejas son parte del feto como un todo. Eielson juega con el fenómeno de la contigüidad, por eso, se trata de un poema metonímico: la silla se halla yuxtapuesta al hablante y esa relación es el fundamento esencial del universo representado. No obstante, el campo figurativo de la antítesis se evidencia en ambos textos. Belli opone la luz a la niebla; la cisterna, al cieno. Eielson remarca el empleo del oxímoron "muriendo 
suavemente", donde la suavidad contrasta, sin duda, con la prontitud de la caída como posible causa de muerte.

"Poema" y "Via della Croce" emplean algunos recursos argumentativos. En el texto de Belli se utiliza el argumento de la coexistencia que se fundamenta en caracterizar al feto como un personaje que sufre una carencia física y, por lo tanto, no es valorado en el mundo. Asimismo, observamos el empleo el argumento de la dirección debido al tránsito doloroso desde el vientre al infierno terrenal, hecho que se percibe también en "Via della Croce", pues se subraya la metáfora de la caída y el baile posterior del locutor con su silla. Sin embargo, en el discurso poético de Eielson, predomina un tono más hipotético ("tengo la impresión") para echar luz sobre la soledad del ser humano en el universo representado.

En los dos poemas, predomina la ausencia de amor. En "Poema", el feto no es amado por su carencia física y, tal sentido, es marginado. Por su parte, en "Via della Croce", el locutor recalca con insistencia que no ha comido ni bebido ni amado. En fin, podríamos seguir comparando las figuras retóricas y las estructuras argumentativas que se revelan en ambos poemas. Sin embargo, consideramos que los dos personajes que aparecen en el poema trasuntan un sentimiento profundo de soledad.

\section{Conclusión}

Los argumentos y recursos figurativos antes mencionados, utilizados por Belli y Eielson, son procedimientos persuasivos que sirven al locutor para convencer al alocutario. Además, muestran, de modo ostensible, cómo ambos poetas construyen textos para persuadir al auditorio a través de una amplia gama de figuras retóricas y técnicas argumentativas. Dicha perspectiva abre la posibilidad para investigar el funcionamiento de estas últimas en otros autores latinoamericanos imprescindibles como Pablo Neruda, César Vallejo o Nicanor Parra.

Sobre la base de la estructura argumentativa de sus poemas, Belli y Eielson realizan una crítica demoledora de los sectores dominantes de la sociedad peruana que han ejercido la violencia como práctica cotidiana y así han impuesto un discurso que margina y excluye al sujeto pobre, centro de la reflexión de Neruda y Vallejo en Canto general y Poemas humanos, respectivamente. 
Además, Belli y Eielson evidencian un manejo notable del lenguaje poético. Esa es una de las principales razones por las cuales constituyen dos momentos fulgurantes de la literatura latinoamericana.

\section{Bibliografía}

Albaladejo, T. Retórica. Madrid: Editorial Síntesis, 1991.

Albaladejo, T. "Poética, Literatura comparada y análisis interdiscursivo". Acta literaria 29.2 (2008): 245-275.

Albaladejo, T. "La poliacroasis en la representación literaria". Castilla 0 (2009): 1-26.

Arduini, S. Prolegómenos a una teoría general de las figuras. Murcia: Universidad de Murcia, 2000.

Arduini, S. La ragione retorica. Sette studi. Rimini: Guaraldi, 2004.

Bajtín, M. Problemas de la poética de Dostoievski. México, D.F.: Fondo de Cultura Económica, 1986.

Bajtín, M. Teoría y estética de la novela. Madrid: Taurus, 1989.

Belli, C. G. Los versos juntos (1946-2008). Prólogo de Mario Vargas Llosa. Sevilla: Sibila y Fundación BBVA, 2008.

Bottiroli, G. Retorica. L'intelligenza figurale nell'arte e nella filosofía. Torino: Bollati Boringhieri, 1993.

Bottiroli, G. Teoria dello stile. Firenze: La Nuova Italia Editrice, 1997.

Bottiroli, G. Che cos'è la teoría della letteratura. Torino: Giulio Einaudi Editore, 2006.

Cánepa, M.A. Lenguaje en conflicto: la poesía de Carlos Germán Belli. Madrid: Editorial Orígenes, 1987.

Canfield, M. L. "Largo viaje del cuerpo hacia la luz". En Martha L. Canfield (Ed.) Jorge Eduardo Eielson: nudos y asedios críticos. Madrid: Iberoamericana y Vervuert, 2002. 97-126.

Cornejo Polar, J. La poesía de Carlos Germán Belli (una aproximación). Lima: Universidad de Lima, 1994.

Eielson, J. E. Poesía escrita. Bogotá: Editorial Norma, 1998. 
Escobar, A. Antología de la poesía peruana. 2 tomos. Lima: Editorial Peisa, 1973.

Fontanier, P. Les figures du discours. Paris: Flammarion, 1977.

Fernández Cozman, C. Las huellas del aura. La poética de Jorge Eduardo Eielson. Lima-Berkeley: Latinoamericana Editores, 1996.

Fernández Cozman, C. El cántaro y la ola. Una aproximación a la poética de Octavio Paz. Lima: Asamblea Nacional de Rectores, 2004.

Fernández Cozman, C. Casa, cuerpo. La poesía de Blanca Varela frente al espejo. Lima: Universidad San Ignacio de Loyola, 2010.

Fernández Cozman, C. Sujeto, metáfora, argumentación. Lima: Universidad San Ignacio de Loyola, 2011.

Fernández Cozman, C. El poema argumentativo de Wáshington Delgado. Lima: Editorial Ornitorrinco y Universidad Santiago Antúnez de Mayolo, 2012.

Fernández Cozman, C. Fulgor en la niebla. Recorridos por la poesía peruana contemporánea. Lima: Universidad San Ignacio de Loyola, 2014a.

Fernández Cozman, C. "La poliacroasis y el referente prehispánico en 'Alturas de Macchu Picchu' de Pablo Neruda". Alma Mater 1 Vol. 1 (2014b):19-26.

Fernández Cozman, C. Las técnicas argumentativas y la utopía dialógica en la poesía de César Vallejo. Lima: Cátedra Vallejo y Universidad Ricardo Palma, 2014c.

Fontanier, P. Les figures du discours. Paris: Flammarion, 1977.

García Berrio, A. Teoría de la literatura. Madrid: Cátedra, 1989.

Groupe u. [1970]. Rhétorique générale. Paris: Éditions du Seuil, 1982.

Hill, N. W. Tradición y modernidad en la poesía de Carlos Germán Belli. Madrid: Editorial Pliegos, 1985. 
Lakoff, G. \& Johnson, M. Metaphors We Live By. Chicago and London: The University of Chicago Press, 2003.

Lotman, Y. Estructura del texto artístico. Madrid: Istmo, 1978.

Morillo, A. La poética nodal: el nudo y su fundamentación estética en la poesía escrita de Jorge Eduardo Eielson. Lima: Fondo Editorial de la Universidad Nacional Mayor de San Marcos y Paracaídas Editores, 2014.

Neruda, P. Canto general. Barcelona: Bruguera, 1980.

Paoli, R. "Razón de ser del neoclasicismo de Carlos Germán Belli". En Miguel Ángel Zapata (Ed.). El pesapalabras: Carlos Germán Belli frente a la crítica. Lima: Ediciones Tabla de Poesía Actual, 1994. 41-53.

Perelman, C. \& Olbrechts-Tyteca, L. Traité de l'argumentation. Bruxelles: Éditions de la Université de Bruxelles, 2008.

Rowe, W. "Palabra, imagen, espacio". En Martha L. Canfield (Ed.). Jorge Eduardo Eielson: nudos y asedios críticos. Madrid: Iberoamericana y Vervuert, 2002. 83-95.

Sandoval, R. "El cuerpo y la noche oscura". En Martha L. Canfield (Ed.) Jorge Eduardo Eielson: nudos y asedios críticos. Madrid: Iberoamericana y Vervuert, 2002. 127-139.

Sobrevilla, D. "La poesía de Carlos Germán Belli: una cumbre de la poesía peruana". En Miguel Ángel Zapata (Ed.). Asir la forma que se va. Nuevos asedios a Carlos Germán Belli. Lima: Fondo Editorial de la Universidad Nacional Mayor de San Marcos, 2006.

Vallejo, C. Obra poética completa. Edición, prólogo y notas de Ricardo González Vigil. Lima: Banco de Crédito, 1991. [Obras completas, T. 1]. 